\title{
FEIRA DO LIVRO DE SANTA MARIA 2019: PRÁTICAS DE COMUNICAÇÃO INTEGRADA ${ }^{1}$
}

\author{
SANTA MARIA BOOK FAIR 2019: \\ PRACTICES OS INTEGRATED COMMUNICATION
}

\section{Vitória Pereira ${ }^{2}$, Carlos Alberto Badke ${ }^{3}$, Graziela Frainer Knoll ${ }^{4}$ e Taís Steffenello Ghisleni ${ }^{5}$ RESUMO}

A Feira do Livro de Santa Maria é um evento literário e cultural que acontece anualmente na cidade e engloba as demais regiões do Estado. Em 2019, a Feira completou sua $46^{a}$ edição com uma campanha publicitária criada e produzida por um grupo de acadêmicos do curso de Publicidade e Propaganda da Universidade Franciscana e mediada pela turma da disciplina de Assessoria Integrada de Comunicação. Com uma proposta multidisciplinar entre as disciplinas, o objetivo do presente artigo é desenvolver um relato de experiência das práticas envolvidas na comunicação integrada da Feira do Livro, bem como descrever o processo de criação e produção da campanha publicitária. Dessa forma, o artigo apresenta o relato e a reflexão da importância da elaboração de uma comunicação integrada e suas etapas antes, durante e depois do evento.

Palavras-chave: Comunicação; Campanha publicitária; Comunidade.

\begin{abstract}
Santa Maria Book Fair is a literary and cultural event that takes place annually in the city and encompasses other regions of Rio Grande do Sul State. In 2019, this fair completed its 46th edition with an advertising campaign created and produced by a group of academics from the Advertising and Marketing course at the Franciscan University and mediated by the Integrated Communication Advisory class. With a multidisciplinary proposal between the disciplines, the objective of this article is to develop an experience report of the practices involved in the integrated communication of the fair, as well as to describe the process of creation and production of the advertising campaign. Thus, this article presents the report and the reflection on the importance of developing an integrated communication and its stages before, during and after the event.
\end{abstract}

Keywords: Communication; Advertising campaign; Community.

\footnotetext{
${ }^{1}$ Iniciação Científica. Artigo publicado nos Anais do SEPE 2019, da Universidade Franciscana.

${ }^{2}$ Acadêmica do Curso de Publicidade e Propaganda - UFN. E-mail: vitoriakrpereira@gmail.com

${ }^{3}$ Professor dos Cursos de Jornalismo e Publicidade e Propaganda - UFN. E-mail: bebsthefabs@hotmail.com

${ }^{4}$ Professora dos Cursos de Publicidade e Propaganda, Mestrado em Ensino de Humanidades e Linguagens e Jogos Digitais - UFN. E-mail: grazi.fknoll@gmail.com

${ }^{5}$ Professora dos Cursos de Publicidade e Propaganda e do Mestrado em Ensino de Humanidades e Linguagens - UFN. E-mail: taisghisleni@yahoo.com.br
} 


\section{INTRODUÇ̃̃O}

A Feira do Livro de Santa Maria é um evento literário e cultural realizado anualmente na cidade e abrange também outras cidades do Estado. Oferece acesso a um vasto catálogo de gêneros literários e possui mais de quarenta estandes fixos, tendo por propósito oferecer e incentivar o hábito da leitura para diversas pessoas. Sua primeira edição ocorreu em 1973 por iniciativa de acadêmicos dos cursos de Comunicação Social da Universidade Federal de Santa Maria (UFSM), que tinham como propósito trazer à cidade um espaço de caráter democrático, cultural e literário para trocas de livros. Desde o início, a principal proposta da Feira foi viabilizar o acesso às variadas obras e títulos restritos e, de modo geral, propagar o hábito da leitura para a comunidade.

Assim, na sua divulgação, o evento sempre contou com a realização de campanhas publicitárias criadas por acadêmicos. Segundo Ferrari et al. (2016, p.96) “a procura por livros de vestibulando, best sellers, títulos juvenis e livros especializados têm movimentado a Feira do Livro de Santa Maria". Ademais, foi a partir do ano 2000 que aconteceu a inclusão de uma programação cultural em paralelo à venda de livros, a fim de agregar e fortalecer o âmbito cultural do evento.

O evento consegue, assim, movimentar a cidade e a sua população em prol de um objetivo: incentivar o hábito à leitura, dando acesso e viabilizando obras, lançamentos, rodas de conversa com autores e apresentações e oficinas culturais (FERRARI et al., 2016). E, por ser um evento de grande importância para a cidade, conta com uma numerosa equipe de gestores. Na campanha de 2019, os alunos da disciplina de Assessoria de Comunicação Integrada da UFN ficaram encarregados da divulgação do material publicitário, criado em outra disciplina do mesmo curso, e também de realizar uma participação ativa antes, durante e após a edição da feira.

Em 2019, a Feira do Livro de Santa Maria chegou a mais uma edição com uma campanha publicitária criada e produzida por um grupo de acadêmicos na disciplina de Direção de Arte do curso de Publicidade e Propaganda da Universidade Franciscana (UFN). A campanha, chamada de "campanha do Bloblô" foi conduzida pela turma de Assessoria Integrada de Comunicação, do curso de Publicidade, com uma proposta multidisciplinar entre essa disciplina e a disciplina de Assessoria de Imprensa, do curso de Jornalismo. A campanha foi divulgada em mídias on-line e também obteve, de forma espontânea, divulgação em veículos tradicionais da cidade.

A comunicação integrada ou comunicação organizacional, de acordo com Oliveira e Paula (2008, p. 21) se processa nas interfaces com outros campos, tais como o campo comunicacional e proporciona interações entre organizações e atores sociais. Além de trabalhar também os fluxos informacionais e relacionais, isto é, as ações e os instrumentos que foram utilizados para a veiculação de determinada informação e as oportunidades de interação e reunião entre organizações e atores sociais. Desse modo, os fluxos visam auxiliar na construção de sentidos sobre o que foi feito, ou seja, as diferentes ações de uma organização para com o ambiente. 
Além disso, favorece a interação da organização com a sociedade e cria mecanismos que possibilitam a validação pública da sua atuação e conduta. Engloba políticas e estratégias de comunicação elaborados a partir dos valores e objetivos da organização, numa dimensão articulada à gestão organizacional, bem como às expectativas e demandas dos atores sociais com os quais interage (OLIVEIRA; PAULA, 2008, p. 21).

A partir do contexto exposto, o objetivo deste artigo é realizar um relato de experiência das práticas envolvidas na comunicação integrada da Feira do Livro de Santa Maria 2019, descrevendo o processo de criação e produção da campanha publicitária desse evento. Para isso, o trabalho utiliza a abordagem qualitativa, método descritivo e apresenta o relato e a reflexão da importância da elaboração de uma comunicação integrada e as suas etapas neste grande evento cultural e literário que é a Feira do Livro.

É importante a ênfase dada às etapas da comunicação integrada no processo criativo e promocional da campanha publicitária da Feira do Livro de Santa Maria 2019 por retratar a construção do processo que gerou os resultados de comunicação. Isso posto, o artigo está organizado em seções da seguinte maneira: inicia com o conceito de campanha publicitária e a descrição do processo de criação e produção, passa para a definição de assessoria integrada de comunicação e as atividades do processo, com a seção sobre o método da pesquisa, com o relato de experiência sobre a importância de inserir a comunicação integrada nas atividades e finaliza com as considerações finais.

\section{METODOLOGIA}

Este artigo decorre de uma pesquisa de abordagem qualitativa do tipo descritiva. A pesquisa qualitativa se propõe "a colher e analisar dados descritivos, obtidos diretamente da situação estudada" (MICHEL, 2005, p.40). A pesquisa exploratória, ou as pesquisas exploratórias visam "proporcionar maior familiaridade com o problema, com vistas a torná-lo mais explícito ou a construir hipóteses. Pode-se dizer que essas pesquisas têm como objetivo principal o aprimoramento de ideias ou a descoberta de intuições (GIL, 1994, p.45). "A pesquisa exploratória envolveu conceitos relacionados ao planejamento e à criação da campanha publicitária” (FERRARI et al., 2016).

O método descritivo ou pesquisa descritiva "verifica, descreve e explica problemas, fatos ou fenômenos da vida real, com a precisão possível, observando e fazendo relações, considerando a influência que o ambiente exerce por eles" (MICHEL, 2005, p.54). Para isso, foi feito um relato de experiência das práticas de comunicação integrada na Feira do Livro 2019, onde foi descrito o processo criativo da campanha e as atividades que a cadeira de assessoria integrada de comunicação efetivou antes, durante e depois do evento lítero cultural. Essa descrição finalizou com a reflexão sobre as práticas da comunicação integrada no processo criativo.

A veiculação e divulgação da campanha da Feira do Livro 2019 ocorreu na disciplina de Assessoria de Imprensa no curso de Propaganda da Universidade Franciscana. Foi durante o $1^{\mathrm{o}}$ semestre do 
ano que os alunos da cadeira de assessoria receberam a tarefa do semestre: administrar a campanha da Feira do Livro 2019 que trazia em sua construção, diferentes peças para diferentes meios de veiculação. A partir do briefing captado no semestre passado, na disciplina de Direção de Arte, apresentado pelo professor Carlos Alberto Badke, a turma dividiu-se em grupos, de no máximo, 5 pessoas, orientados pelos professores da disciplina, para administrar e realizar a comunicação nos meios online e offline. Os procedimentos para a efetivação da campanha publicitária, durante as aulas, foram sistematizados da seguinte maneira: divisão dos grupos e das tarefas antes e durante a Feira do Livro; Grupo 1) responsável pelo press kit; Grupo 2) responsável pelas peças e materiais gráficos; Grupo 3) responsável para entrar em contato com a mídia; Grupo 4) responsável pela rede social Facebook; Grupo 5) responsável pela rede social Instagram; e todos os grupos encarregados de relatório de análise e resultados das tarefas executadas antes, durante e após a realização da Feira.

\section{CONTEXTUALIZAÇÃO DA CAMPANHA PUBLICITÁRIA}

A campanha publicitária realizada para a Feira do Livro de Santa Maria 2019 iniciou com a apresentação da proposta aos alunos das disciplinas de Direção de Arte e Produção Gráfica ${ }^{6}$ do curso de Publicidade e Propaganda da Universidade Franciscana, com orientação da professora Graziela Frainer Knoll. O trabalho iniciou como um trabalho de disciplinas e culminou na seleção de duas campanhas finalistas que foram apresentadas no dia onze de março de 2019 para a prefeitura da cidade, já que o evento é municipal.

Vale ressaltar que a publicidade se utiliza da campanha publicitária para divulgar uma mensagem, pois, conforme Rocha (1995), é como um sistema de ideias que, materializadas em formato de mensagem, circulam por meio de um contexto social e cultural. Assim, a partir dessa relação com o público, as ideias podem chegar de forma direta ou indireta e serem visualizadas como um caminho para a compreensão e criação de relações, comportamentos e ideologias.

Para melhor compreender o processo de produção de uma campanha publicitária, existe necessidade de gerar um esforço de comunicação e, segundo Sant’Anna, Júnior e Garcia (2009), toda vez que se fala em esforço publicitário, é de extrema importância que este seja embasado em conhecimento, de produto, de mercado, do consumidor, da concorrência, das tendências, etc. Esse embasamento deve ser bem analisado, pois as pessoas tendem a não ser constantes, isto é, suas percepções, seus valores, personalidades e opiniões podem mudar de forma contínua, para tanto, é necessário um grande esforço e estudo para a veiculação de campanhas publicitárias.

A primeira etapa para construção e materialização de uma mensagem publicitária é a orientação inicial: quem é o cliente e o que este gostaria, ou seja, a captação do briefing ${ }^{7}$. No caso da campanha

${ }^{6}$ Atualmente, essas disciplinas encontram-se reunidas em Projeto Gráfico na nova matriz curricular do curso.

${ }^{7} \mathrm{O}$ briefing é um documento que contém as informações preliminares, além disso, ele possui todas as instruções que o cliente fornece à agência para orientar os trabalhos (SANT'ANNA; JÚNIOR; GARCIA, 2009). 
publicitária para o espaço literário e cultural dos livros, a Feira do Livro é o cliente e a captação do briefing deu-se por meio da fala do professor e um dos organizadores do evento, Carlos Alberto Badke, que apresentou às turmas a história do evento e o que poderia ser útil para o conhecimento prévio sobre o cliente.

Conforme Corrêa (2008), existem algumas perguntas norteadoras que devem ser levadas em consideração durante a captação das informações, tais como: quem? o que? como? onde? e quando? Logo, nota-se que o briefing é uma das partes essenciais para que os criativos possam ter amplo entendimento do que deverá ser feito antes, durante e depois de a campanha ser planejada e criada. Depois de feito o levantamento acerca das principais informações sobre o cliente, outra etapa de grande importância é o planejamento. Para a criação da Campanha da Feira do Livro de Santa Maria 2019, o grupo que concorreu com outros grupos de acadêmicos para a criação da campanha desse cliente foi composto pelos discentes Gabriel Ávila, João Paulo Antunes e Milena Denardin. Logo após a captura do briefing, o grupo passou a participar do planejamento de comunicação da campanha, com etapas de pesquisa, criação e produção das peças publicitárias. Conforme Sant’Anna, Júnior e Garcia (2009), é o planejamento que centraliza, coordena e conecta todas as variáveis necessárias à realização dos objetivos de uma campanha.

Dessa forma, a etapa de pesquisa pré-ordena o que irá conter, de fato, o plano final, por isso, é de suma importância estabelecer um momento inicial com enfoque na busca por referências, isto é, uma etapa importante de pesquisa. Afinal, o planejamento de comunicação determina as diretrizes, os objetivos e estratégias de comunicação que serão realizadas, tendo em conta que já haja um planejamento de marketing existente ou norteador (CORRÊA, 2008). Foi a partir da estruturação do planejamento que a campanha publicitária começou a ganhar vida, passando ao brainstorm, que consiste em um processo de geração de ideias, técnica em que o grupo se reúne para pensar em várias propostas e temas oportunos para a campanha do cliente (RABAÇA; BARBOSA, 2002). Após a definição do tema e do conceito criativo da campanha, a criação da redação, isto é, o texto verbal das peças e a produção do design gráfico, a mensagem publicitária vai se materializando e tomando forma.

Diante da pesquisa de temas anteriores e de referências, o grupo de alunos percebeu que a ilustração e a criação de um personagem emblemático para essa edição do evento seria um recurso atrativo potencialmente, já que nos últimos anos havia sido bastante explorada a imagem fotográfica nas campanhas de edições anteriores. Assim foi criado Bloblô, mascote do evento dos livros em 2019, que surgiu para validar a proposta de uma maneira lúdica e criativa, com peças gráficas que exploravam mundos de fantasia. $\mathrm{O}$ mascote foi, portanto, um dos principais diferenciais para expressar a mensagem proposta pela campanha publicitária. 


\section{CRIAÇÃO E PRODUÇÃO DA CAMPANHA}

A campanha do Bloblô elaborada para a $46^{\mathrm{a}}$ edição da Feira do Livro teve como design gráfico a ilustração digital. O mascote "Bloblô, foi feito a partir do desenho digital, presente em todas as peças impressas e digitais, assim como o selo da campanha que trouxe em sua arte a assinatura em tipografia manuscrita, no caso, o slogan da campanha que sintetiza toda a ideia presente nos materiais: "Devore um livro para descobrir novos mundos".

A criação e a produção da campanha foram feitas de forma colaborativa, foi o grupo vencedor que criou toda a estética e a ideia principal da campanha, e na sequencia os outros colegas participaram ativamente da produção, isto é, da veiculação e divulgação dos materiais desenvolvidos para o meio offline e online. Vale lembrar que a campanha do evento dos livros de 2019 foi produzida de forma a contemplar o público-alvo. A partir dos elementos visuais, isto é, da composição visual utilizada na campanha, tais como: ilustrações digitais, imagens, lettering, tipografias e cores, a mensagem criada pode ser destinada assim, ao público definido durante a realização do briefing.

A imagem possui, basicamente, dois tipos, a fotografia e a ilustração. A escolha da ilustração digital para o layout da campanha de 2019 foi pensada de modo estratégico: criar lembrança no público e aproximá-los do mundo da imaginação, tal qual os livros possibilitam. Afinal, a ilustração permite, especialmente, a entrada no mundo da fantasia, já a fotografia tende a estabelecer um efeito de realidade na peça (BURTENSHAWN; MAHON; BARFOOT, 2010). A escolha da paleta de cores em cada peça e da campanha em geral, segue uma linha estética. Por ser desenhos ilustrados, a preferência por tons terrosos e cores primárias para a composição foi seguida em todos os materiais de divulgação. Segundo Farina, Perez e Bastos (2011), as cores influenciam a forma como o ser humano percebe as mensagens de comunicação e, inclusive, os ambientes.

A concepção visual das peças da campanha beneficiou-se dos recursos ilustrativos para a exploração de metáforas que condizem com o mundo da imaginação, que os livros e a leitura possibilitam para o leitor. A figura 1 contém os três cartazes criados pelo grupo vencedor, referentes as duas mídias principais para a veiculação e divulgação das peças, isto é, meio online e off-line. 
Figura 1 - Cartazes Feira do Livro de Santa Maria 2019.
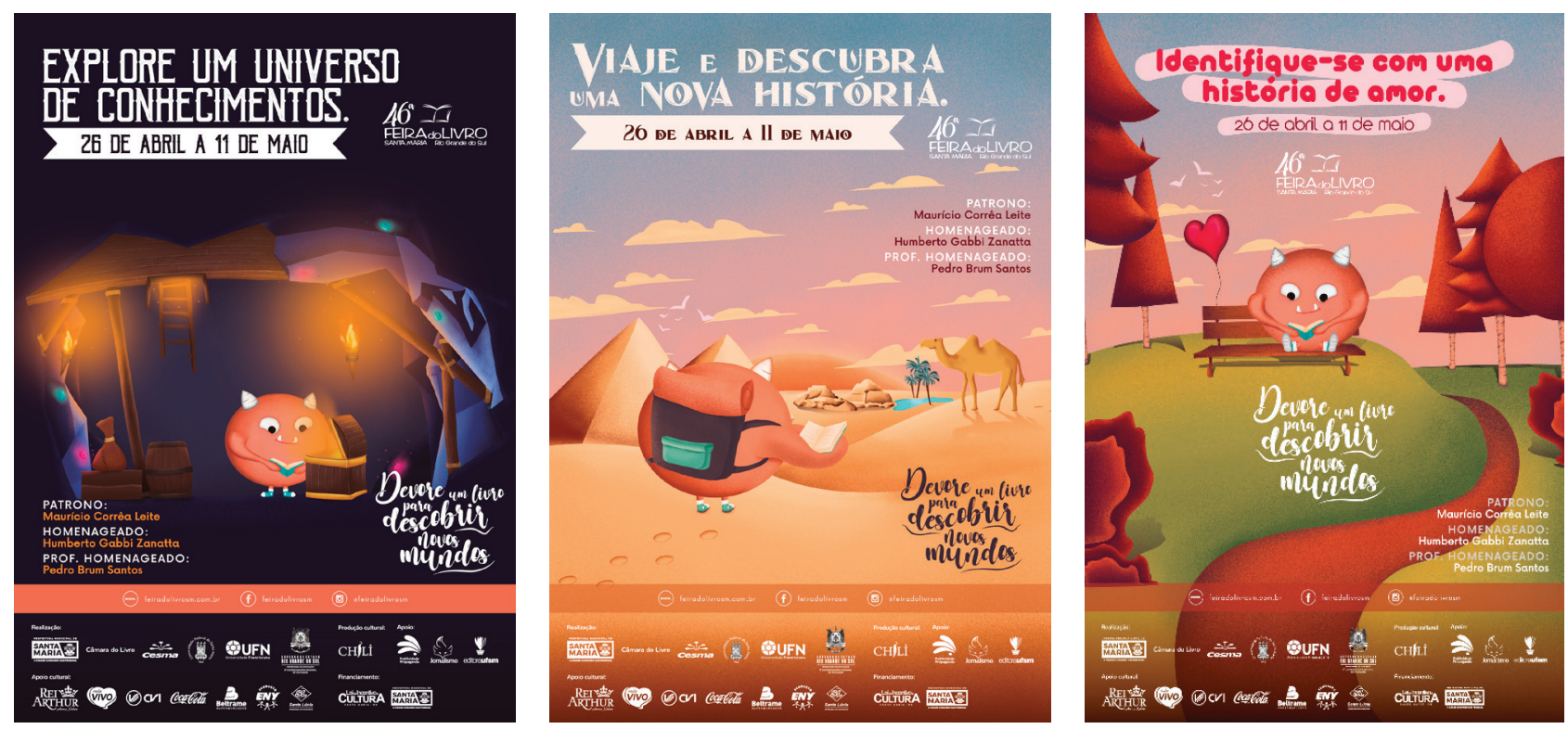

Fonte: elaboração do grupo de acadêmicos formado por Gabriel Ávila, João Paulo Antunes e Milena Denardin.

Nas imagens, Bloblô, mascote da Feira do Livro de Santa Maria 2019, está sempre com o seu livro em mãos e em consonância com o conceito da campanha: devorar um livro para descobrir novos mundos. O conceito consistiu em mostrar, a partir da idealização dos layouts com ilustrações, que a partir da leitura, o leitor tem a chance de descobrir novos mundos e expandir o seu imaginário devorando as boas páginas de um livro. Com esse intuito, o personagem Bloblô foi criado por meio de protótipos e, aos poucos, com muitas referências e tentativas, a versão final foi realizada. Obviamente, por ser uma campanha de alguns meses de preparo e veiculação, ocorreram alterações e ajustes para melhorar ainda mais o trabalho final, expressando a ideia da melhor maneira aos diferentes públicos da Feira do Livro.

Para cada cartaz, foram criadas redações condizentes com a temática escolhida. Em cada uma das peças, a chamada expressa o quão importante é a leitura para disseminar novos conhecimentos e descobrir, a partir da imaginação, mundos até então inexplorados. Nas peças, foram representadas três situações remetentes a cada gênero literário: Bloblô explorando uma caverna - gênero suspense; Bloblô aventurando-se no deserto - gênero aventura; Bloblô emocionando-se com uma história de amor - gênero romance.

As cores dos cartazes e das peças secundárias, como postagens para redes sociais e marca-páginas, foram pensadas a partir da psicodinâmica das cores, relacionadas ao significado a que cada uma delas remete (FARINA; PEREZ; BASTOS, 2011). Assim, cada peça possui uma escala de cores diferentes, indo de tonalidades frias (azul e verde) a tonalidades quentes (vermelho, laranja e coral), assim como a tipografia utilizada, de estilo fantasia. Esse cuidado na composição visual da campanha 
reside no fato de que, em publicidade, os diferentes componentes das peças devem ser pensados em conjunto e de forma estratégica, além de criativa.

\section{ASSESSORIA INTEGRADA DE COMUNICAÇÃO}

A comunicação integrada da Feira do Livro de Santa Maria 2019 teve apoio da multidisciplinaridade entre as disciplinas de Assessoria de Comunicação e Assessoria de Imprensa, disciplina que é do curso de Jornalismo. A comunicação integrada, conforme afirma Kunsch (2003, p. 150) é uma filosofia que direciona a convergência das diversas áreas, permitindo uma atuação sinérgica. Durante a disciplina de Assessoria de Comunicação Integrada, ministrada pelos professores Taís Steffenello Ghisleni e Carlos Alberto Badke, os alunos do quinto semestre do curso de Publicidade e Propaganda ficaram responsáveis, a partir da formação de equipes, por uma área de atuação, como por exemplo: montar o press kit, administrar as redes sociais oficiais do evento e medir as métricas, fazer contato direto com os veículos e assessorar a campanha de comunicação da $46^{\mathrm{a}}$ edição da Feira do Livro de Santa Maria juntamente com os assessores de imprensa do evento.

Kunsch (2003, p. 150) explica que a comunicação integrada "pressupõe uma junção da comunicação institucional, da comunicação mercadológica, da comunicação interna e da comunicação administrativa, que formam o mix, o composto da comunicação organizacional". Assim, para a campanha da Feira do Livro 2019 de Santa Maria/RS, a turma estudou em primeiro lugar, o planejamento da comunicação integrada que seria efetivada antes, durante e após o evento dos livros, pois, segundo afirma Vasconcelos (2009, p. 16), "planejar a comunicação é muito mais do que escolher o que vai ser dito em uma campanha e fazer propaganda em jornais e revistas. É analisar e diagnosticar corretamente um problema específico e encontrar uma solução estratégica [...]”.

O processo de planejamento para assessorar o espaço lítero-cultural teve como suporte o diagnóstico de um problema específico: como estabelecer uma conexão com o público a partir das redes sociais da Feira do Livro da cidade. A partir dessa problemática, e conforme propõe Kunsch (2003, p. 4) o planejamento constitui um processo complexo e abrangente e possui dimensões e características próprias, implicando também em uma visão filosófica e com bases em políticas definidas, sendo direcionado por princípios gerais e específicos. A atividade de planejar evita que ações das organizações sejam executadas ao acaso, sem qualquer preocupação com a eficiência, a eficácia e a efetividade para o alcance dos resultados (KUNSCH, 2003, p. 216).

A comunicação integrada começou bem antes do evento dos livros chegar na cidade, totalizando-se dois meses de planejamento para, enfim a execução acontecer e gerar os resultados após o término da Feira. O planejamento envolve, portanto, desde a campanha a ser veiculada, até a linguagem com que serão feitas as publicações nas redes sociais oficiais do evento, para poder alcançar seus objetivos de comunicação. 
Depois de todo o esforço destinado ao planejamento, colocam-se em prática as ações idealizadas, o que inicia com a veiculação. Durante a realização da Feira do Livro 2019, os alunos ficaram responsáveis por veicular a campanha, principalmente nos meios de comunicação, seja no espaço on-line, seja no espaço offline. Tendo concluído esses dois momentos que, são essenciais, chega-se ao momento de mensurar os resultados, colocando na balança todas as ações, estratégias e táticas realizadas antes e durante o acontecimento do evento, em pontos positivos e negativos. Essa é a etapa em que são medidos os esforços e, assim, concilia-se o que pode ser melhorado ou o que pode continuar acontecendo na próxima edição.

\section{ATIVIDADES INTEGRADAS NA FEIRA DO LIVRO 2019}

Os alunos do quinto semestre do curso de Publicidade e Propaganda foram os primeiros a realizar, dentro de uma disciplina regular do curso, a assessoria ao evento. Por esse motivo, as ações e estratégias realizadas e cumpridas durante a Feira do Livro visaram qualificar e aferir o que realmente foi assertivo e o que deve ser melhorado. Para tanto, as aulas de Assessoria de Comunicação Integrada foram de grande auxílio para a construção de uma comunicação integrada, envolvendo dois meses de planejamento e preparo, com divisão de tarefas e grupos de até cinco pessoas para a execução dos planos. A divisão dos grupos deu-se por meio de afinidade entre os alunos, e cada um teve por responsabilidade assumir uma função enquanto o evento dos livros acontecia na cidade. Assim, as equipes foram atribuídas com funções, como: criar o press kit e o release para distribuir aos veículos de comunicação, planejar os conteúdos para veicular as mensagens nas redes sociais - Facebook e Instagram - sendo que uma equipe trabalhou nos materiais para serem postados no Facebook, e outra ficou encarregada do conteúdo para ser postado no Instagram; além de finalização da produção dos materiais gráficos da campanha e decisões estratégicas de mídia, incluindo divulgação em rádio.

As atividades iniciaram em 26 de março de 2019, quando foi feita a separação dos grupos e funções, e cada grupo teve até dia 09 de abril para planejar e apresentar sua proposta de atividades, que iniciou na mesma data e se estendeu até o final do evento. Já no dia 14 de maio de 2019, foi apresentado o relatório final da assessoria. Dessa maneira, todas as atividades foram realizadas de forma conjunta, ou seja, as equipes interagiram e compartilharam ações e experiências, de maneira que todas se complementaram a partir da comunicação efetivada.

O grupo responsável pelo press kit teve como principal tarefa pensar em um "brinde" para presentear os veículos de comunicação, o press kit foi composto por um chaveiro em formato de Bloblô - feito artesanalmente - e um livro. A criação de conteúdos on-line e postagens no Facebook principal canal de comunicação da Feira do Livro de Santa Maria - dispôs de variados posts, com postagens interativas e enquetes, fomentou a participação do público na página. Conforme Gullo (2009, p.54), “a persuasão é um fator básico para se obter efetividade nos resultados da comunicação e para 
mobilizar consumidores ou clientes de marcas concorrentes para a nossa marca". No Instagram, a utilização da ferramenta stories foi de grande esforço para conceber fotos, vídeos e gifs dos bastidores e da programação que acontecia em tempo real durante a Feira.

A mídia ficou encarregada de fazer o contato direito para com os veículos de comunicação. É a partir da assessoria de imprensa que muita mídia orgânica é veiculada. A mídia orgânica ou espontânea é uma forma gratuita de dar visibilidade a Feira do Livro. Já a produção do material gráfico, bem como o nome já sugere, foi a responsável por dar vida a todo o material gráfico e impresso da campanha. Todas as peças e conteúdos pensados para o digital era produzido pelo grupo encarregado, sendo este o grupo vencedor da campanha veiculada.

O conhecimento adquirido tanto antes, durante quanto depois da realização da Feira do Livro foi imensurável. A atividade de assessoria de comunicação é um dos momentos onde a teoria e a prática se unem e formam apenas uma forma de aprendizado. Pensar em assessoria de comunicação integrada é difícil, mas executar todas as ações pode ser um desafio ainda maior, visto que a Feira do Livro é um cliente gigante, tanto para os alunos quanto para a cidade que sedia a realização. O desafio foi muito bem aceito e exercido de forma exemplar pelos alunos do quinto semestre de publicidade e propaganda.

\section{CONCLUSÕES}

O desenvolvimento da campanha da Feira do Livro de Santa Maria 2019, assim como acontece em outros anos, tem envolvimento e ajuda da comunidade acadêmica para a sua realização. Conforme observado durante o relato de experiência, é um aprendizado constante para os discentes e docentes do curso de Publicidade e Propaganda compor a equipe da Feira do Livro da cidade, pois o desenvolvimento discorre a partir de um processo de comunicação integrada, por qual diversas disciplinas e saberes podem ser contemplados em consonância durante a efetivação de cada atividade.

Além disso, a participação dos alunos e de toda a comunidade acadêmica é extremamente significativa para o engajamento e a construção da comunicação de forma integralizada entre todos os órgãos que fazem a Feira do Livro acontecer na cidade de Santa Maria. Essa é conhecida por ser a cidade dos jovens universitários, pois abrange em sua história um polo cultural e universitário enorme. Desse modo, a Feira do Livro se torna um espaço em que a cultura e o conhecimento universitário passam a andar juntos e interligados.

Os objetivos de comunicação propostos durante a disciplina de Assessoria de Comunicação Integrada foram concretizados por meio da vasta divulgação e visibilidade que a Feira do Livro de Santa Maria 2019 obteve. Houve destaque para as redes sociais que foram um dos principais meios de comunicação e também pela divulgação nos meios tradicionais, a partir da mídia espontânea, ou 
seja, mídias que não foram pagas, tais como: matérias de jornais e portais de notícias regionais que promoveram maior alcance e extensão na visibilidade do evento na cidade e região.

Nesse contexto, a comunicação integrada realizada antes, durante e após o evento, contribuiu de maneira efetiva para que a comunicação pudesse chegar ao seu destino sem tantos ruídos. A participação dos alunos e professores dos cursos de Publicidade e Propaganda e Jornalismo, por meio de diferentes disciplinas - Assessoria de Comunicação Integrada, Direção de Arte e Assessoria de Imprensa - contribuiu, de forma organizada, para que a edição fosse um sucesso, tanto no engajamento e na participação da comunidade, quanto na imagem da campanha, que foi expressamente aprovada pelo grande público.

Por fim, para a realização de um evento de tanta importância para a cidade, foi necessário aprofundar os estudos, a partir dos processos, métodos e técnicas do campo da publicidade que os alunos aprendem no curso, para enfim colocá-las em execução. Logo, o diálogo entre teoria e prática é de suma importância para os alunos, pois cria a oportunidade de expressar todo o conhecimento adquirido e as habilidades e competências desenvolvidas.

\section{REFERÊNCIAS}

BURTENSHAW, Ken; MAHON, Nik; BARFOOT, Caroline. Fundamentos de publicidade criativa. Porto Alegre: Bookman, 2010.

CORRÊA, Roberto. Planejamento de propaganda. 10. ed. São Paulo: Cangage Learning, 2010.

FARINA, Modesto; PEREZ, Clotilde; BASTOS, Dorinho. Psicodinâmica das cores em comunicação. 6. ed. São Paulo: Blucher, 2011.

FERRARI, Camila Tastch; NASCIMENTO, Letícia Vianna do; BAGGIO, Lucas Fernandes; PORTO ALEGRE, Roberta da Silva; KNOLL, Graziela Frainer. Campanha publicitária da feira do livro de Santa Maria 2016: da divulgação ao incentivo à leitura. Disciplinarum Scientia, Série: Artes, Letras e Comunicação, Santa Maria, v. 17, n. 1, p. 95-105, 2016. Disponível em: https://bit.ly/2UyBadN. Acesso em: 20 de Junho de 2019.

GIL, Carlos Antonio. Métodos e Técnicas de Pesquisa Social. 6.ed. São Paulo: Atlas, 2008.

GULLO, Duda Pinheiro José. Comunicação Integrada de Marketing: gestão dos elementos de comunicação, suporte às estratégias de marketing e de negócios da empresa. 3. ed. São Paulo: Atlas, 2009. 
KUNSCH, Margarida Maria Khohling. Planejamento de relações públicas na comunicação integrada. 2. ed. São Paulo: Summus, 2003.

MICHEL, Maria Helena. Metodologia e Pesquisa Científica em Ciências Sociais: Um Guia Prático para Acompanhamento da Disciplina e Elaboração de Trabalhos Monográficos. 3.ed. São Paulo: Atlas, 2005.

RABAÇA, Carlos Alberto; BARBOSA, Gilberto. Dicionário de Comunicação. São Paulo: Ática, 2002.

ROCHA, Everardo. Magia e capitalismo: um estudo antropológico da publicidade. São Paulo: Brasiliense, 1995.

SAMPAIO, Rafael. Propaganda de A a Z. 4. ed. Rio de Janeiro: Campus Elsevier, 2013.

SANT’ANNA, Armando; JÚNIOR, Ismael Rocha; GARCIA, Luiz Fernando Dabul. Propaganda: teoria, técnica, prática. 8. ed. São Paulo: Cengage, 2009. 